\title{
Applying Yalom's therapeutic factors of group psychotherapy to Alcoholics Anonymous
}

\author{
Stephen Strobbe ${ }^{1}$
}

(iD) https://orcid.org/0000-0001-5651-6741

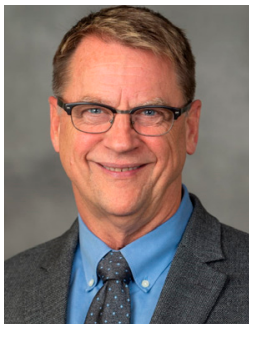

Founded in 1935, Alcoholics Anonymous (AA) has been a mainstay in treatment and recovery from alcoholism on a worldwide basis, with over two million members in

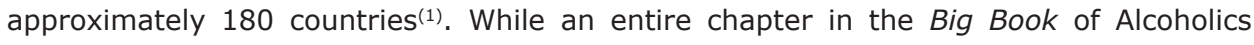
Anonymous is dedicated to "How it Works"(2), clinicians and researchers strive to identify mechanisms of action that can help explain the effectiveness of this mutual help program.

In many respects, the unit of measure in AA is the group rather than the individual, as reflected in the Twelve Traditions ${ }^{(3)}$. In 1970, Irvin Yalom first published The Theory and Practice of Group Psychotherapy, in which he listed 11 "curative factors" of group therapy, later termed "therapeutic factors"(4). The purpose of this brief article is to draw parallels and to provide specific, selected examples of how these therapeutic factors may express themselves in the "spiritual program of action"(2) that is Alcoholics Anonymous.

\section{Installation of Hope}

The A.A. Preamble ${ }^{\odot}$ states, "Alcoholics Anonymous is a fellowship of men and women who share their experience, strength, and hope with each other that they may solve their common problem and help others to recover from alcoholism"(5). In AA meetings, individuals encounter others-with various lengths and qualities of sobriety-who have similarly suffered, and since recovered, from the same malady of mind, body and spirit, thereby offering a practical message of hope.

\footnotetext{
${ }^{1}$ University of Michigan, School of Nursing at Ann Arbor, Michigan, U.S.A.
}

\section{How to cite this article}

Strobbe S. Applying Yalom's therapeutic factors of group psychotherapy to Alcoholics Anonymous. SMAD, Rev Eletrônica Saúde Mental Álcool Drog. 2020;16(2):1-4. doi: https://dx.doi.org/10.11606/issn.1806-6976.smad.2020.0090. 


\section{Universality}

Alcoholics Anonymous was predicated on the basis of one alcoholic talking to another. Many of those with alcohol use disorders falsely believe they are unique in their circumstances, shortcomings and transgressions. These thoughts are often accompanied by feelings of inadequacy, guilt and shame, with subsequent behaviors of secretiveness, dishonesty and isolation. By hearing open and honest accounts from others and reading personal stories in the Big Book (which has evolved to better reflect the changing membership over time), these individuals come to identify with those who have thought, felt, and behaved similarly. As a result, they may come to realize they are not alone, and can acknowledge, "...and I am an alcoholic."

\section{Imparting Information}

The imparting of information takes many forms in Alcoholics Anonymous. These include attendance at open meetings (which anyone may attend), closed meetings (limited to self-identified members, or those who have a desire to stop drinking), and open talks, in which a speaker shares his/her personal story, describing, "...what we were like, what happened, and what we are like now"(2). Other sources of information include slogans, such as, "Easy Does It," conference-approved literature, and web sites. Some meetings take the form of study sessions, during which members take turns reading from the Big Book, or The Twelve Steps and Twelve Traditions ${ }^{(3)}$, and responding. A sponsor, generally someone who has already worked the 12 steps of Alcoholics Anonymous, serves as a guide or mentor to newer members, and beyond.

\section{Altruism}

Traditional definitions of altruism often refer only to behaviors that benefit others ${ }^{(6)}$. In terms of psychotherapy, this has been described as a more dynamic, bidirectional relationship in which the giver also benefits by helping others-and so it is in Alcoholics Anonymous ${ }^{(4)}$. In a symbol frequently used to depict $A A$, one of the sides of a triangle is labeled, service. "Sobriety can't be kept unless it is given away"(3). One chapter in the Big Book is dedicated to "Working with Others," and begins with the statement, "Practical experience shows that nothing will so much insure immunity from drinking as intensive work with other alcoholics"(2).

\section{The Corrective Recapitulation of the Primary Family Group}

Since genetics, environment, and personal characteristics play significant roles in the etiology of alcoholism, it is not surprising that many members of AA describe unhealthy, damaged and severed family ties. Predictably, these patterns are destined to reemerge in subsequent relationships. Trust is a central issue, whether in trusting others, or in being trustworthy. In Alcoholics Anonymous, a safe, supportive, and respectful environment may promote the development of more secure and assertive behaviors, rather than overly aggressive, passive, or passive-aggressive posturing. By completing a "fearless and thorough moral inventory" (Step 4), sharing this inventory with another human being (Step 5), making a list of all persons they have harmed (Step 8), and making amends (Step 9), members are actively engaged in new behaviors that can lead to increasingly honest and healthy relationships with themselves, a "higher power," and others.

\section{Development of Socializing Techniques}

Individuals may or may not be adequately aware of the ways in which their own behaviors are perceived by, and affect, others. With direct or indirect feedback from a sponsor and peers, completing personal inventories, engaging in personal reflection, and working the steps, members may gain insight into those self-defeating behaviors that have placed them at odds with others, thereby providing opportunities to practice more socially acceptable patterns of interpersonal relationships.

\section{Imitative Behavior}

In $\mathrm{AA}$, both newer and more established members are surrounded by individuals who have learned, with varying degrees of success, how to live "life... on life's terms"(2), without resorting to drinking. Members may witness, firsthand, benefits that come to those who attend meetings, work the steps, and engage in service. As is often the 
case in psychotherapy, the novice may observe, imitate, and adopt attitudes and behaviors-first seen in others-that appear to support recovery, growth, and well-being.

\section{Interpersonal Learning}

While interpersonal learning has been described as "a broad and complex therapeutic factor"(4), certain conditions within Alcoholics Anonymous may help promote this process. First, the underlying psychopathology of alcoholism, whether active or in remission, can be assumed. Given this shared vulnerability among AA members, acceptanceand the ability to extend empathy and compassion toward one another-is cultivated.

Newcomers are often told, "Don't drink, and go to meetings," to attend "90 meetings in 90 days," "Get a sponsor," and "Work the steps." Individuals receive positive reinforcement as they progress in the program. "Monthly milestones" and anniversaries of sobriety are celebrated. Self-esteem is restored and enhanced, and sobriety becomes valued. Even if a member were to relapse, which can and does occur, then he or she is welcomed back, and encouraged to redouble their efforts, "one day at a time." Struggling members-new or old-may be told, "We will love you until you can learn to love yourself."

\section{Group Cohesiveness}

The integrity of the group is of paramount importance, without which alcoholics with a desire to stop drinking would have no place to go. Members are encouraged to identify a "home group," and to attend those meetings faithfully. Individuals come to know and care about one another-and the group itself-in deep and meaningful ways. In a democratic manner, decisions that affect the group are determined by "group conscience." On a broader scale, the "Twelve Traditions" were written to protect AA as a whole, with "unity" as an overarching principle(3).

\section{Catharsis}

For some, the unbridled expression of emotions comes far too easily. For others, feelings may be intimidating, avoided, or repressed. In group psychotherapy, catharsis is viewed as a necessary but insufficient condition, and one that came to be overrated, even by Freud himself(4). Following the publication of the Big Book in 1939, many of the writings of Bill Wilson, one of the co-founders of AA, focused on "emotional sobriety," a stable balance between reality-based thoughts, feelings, and actions, which stands as a precursor to cognitive-behavioral therapy (CBT).

\section{Existential Factors}

Existential factors are among the most discomforting-and potentially transcendent-elements of the human condition, including an "awareness of death, freedom, isolation, and life purpose"(4), coupled with the realization "that I must take ultimate responsibility for the way I live my life no matter how much guidance and support I get from others." In the context of Alcoholics Anonymous, meaning comes from being part of something greater than oneself. As reflected by Tradition Five, "Each group has but one primary purpose-to carry its message to the alcoholic who still suffers"(3).

\section{Conclusion}

Although Alcoholics Anonymous functions primarily at the level of groups, most research to date has focused on individuals. While structural differences exist between traditional psychotherapy groups and those in AA, Yalom's therapeutic factors provide a lens through which additional mechanisms of action can be identified, described, and explained in the context of Alcoholics Anonymous.

\section{References}

1. Alcoholics Anonymous World Services. A.A. around the world, 2019. Disponível em: https://www.aa.org/pages/ en_US/aa-around-the-world-

2. Alcoholics Anonymous World Services. Alcoholics Anonymous: The story of how thousands of men and women have recovered from alcoholism. $4^{\text {th }}$ ed. New York, NY; 2001.

3. Alcoholics Anonymous World Services. The twelve steps and twelve traditions. New York, NY; 1953. 
4. Yalom ID, Leszcz M. The theory and practice of group psychotherapy. $5^{\text {th }}$ ed. New York, NY: Basic Books; 2005.

5. Alcoholics Anonymous World Services. A.A. preamble, 2013. Disponível em: https://www.aa.org/assets/en_US/ smf-92_en.pdf

6. Merriam-Webster. Merriam-Webster's collegiate dictionary. $11^{\text {th }}$ ed. Springfield, MA; 2004. 